\title{
Implementation of Power Demand Response Trading System for New Energy Consumption
}

\author{
Yi ZHANG ${ }^{1,2, a}$, Feng ZHANG ${ }^{3}$, Youchun $\mathrm{LI}^{3}$,Jianqiang $\mathrm{CAI}^{3}$, Yang $\mathrm{LI}^{3}$ and $\mathrm{Lv}_{\mathrm{TANG}}{ }^{3}$ \\ ${ }^{1}$ The School of Electrical Engineering,Zhejiang University of Water Resources and Electric Power,Hangzhou, 310007, China \\ ${ }^{2}$ The Zhejiang-Belarus Joint Laboratory of Intelligent Equipment and System for Water Conservancy and Hydropower Safety Monitoring \\ ${ }^{3}$ State Grid Zhejiang Electiric Power CO. LTD,Hangzhou, 310007, China
}

\begin{abstract}
Demand response adjusts demand through market signals such as price to promote grid reliability. By changing the demand for electricity, the demand response can realize the friendly interaction of sourcenetwork-load, promote the absorption of new energy, and thus applying to the rapid growth of the scale of new energy installation. Considering the characteristics of provincial power grid, this paper studies the power demand response trading organization and technology realization from the point of view of promoting clean energy consumption, and realizes it systematically. This method has universal application value for the same type of provincial power grid.
\end{abstract}

\section{Introduction}

In recent years, the growth rate of new energy installed such as nuclear power, wind power and solar photovoltaic power generation is higher than that of traditional power supply, and the proportion of total installed capacity of power generation in China is increasing ${ }^{[1-2]}$. Due to the factors of grid structure, load characteristics and power grid safety, the new energy grid absorption is limited, and the phenomenon of abandoning wind and light in local period exists. In order to solve this problem, the demand response can be used to guide the power demand to change through market signals such as price, so as to adapt to the characteristics of new energy generation and improve the level of new energy consumption. Considering the characteristics of provincial power grid, this paper constructs a provincial power demand response trading system suitable for new energy consumption from the point of view of source network load linkage, and realizes $i^{[3-5]}$.

\section{Impact of new energy consumption on electricity demand response}

With the promulgation and implementation of laws and regulations such as the Law of the People's Republic of China on Renewable Energy, the installed capacity of wind power and solar energy in power grids is growing rapidly, and the problems of new energy consumption and its impact on the safe operation of power grids are highlighted. Table 1 takes a provincial power grid as an example,. During the peak period of daytime load, photovoltaic is beneficial to the peak shaving of the power grid, but its output fluctuation requires the power grid to increase the reserve capacity and adjust the

\footnotetext{
${ }^{\text {a }}$ Corresponding author: eezhangf@yeah.net
}

means. During the daytime load trough period, such as holidays, the proportion of photovoltaic power generation is increasing, which puts forward higher requirements for the operation mode of UHV line, the deep peak-shaving and mediation of thermal power units, and the operation of nuclear power reduction. The main problems affecting the absorption of new energy are as follows: first, the degree of power generation fluctuation is large, and the peak shaving of power grid is more difficult. Second, voltage regulation is difficult to balance, power grid reactive power support capacity decline. Third, power quality is more difficult to control, power grid harmonic voltage level beyond the limit. Fourth, the difficulty of load forecasting is increased, and the response to load demand is improved. Under this requirement, changing load demand characteristics through power demand response transaction has positive practical significance for improving new energy ${ }^{[6-8]}$.

Table 1. 2016-2020 new energy capacity in a province $(\mathrm{kW})$

\begin{tabular}{cccc}
\hline Type & 2016 & 2017 & 2020 \\
\hline Wind power & 110.4 & 163.1 & 455.7 \\
\hline photovoltaic power & 413.6 & 652.2 & 1469.6 \\
\hline
\end{tabular}

\section{Electricity Demand Response Trading Organization}

\subsection{Requirements-responsive transaction orga- nization principles}

Based on the principles of "safety and reliability, fairness and equality, openness and transparency ", following the objective laws of market economy and electricity operation, using market mechanism and economic leverage, and according to the three dimensions of" economy-type agreement demand response first, 
emergency real-time demand response second, orderly power management guarantee bottom ", all kinds of subjects are widely mobilized to participate in power demand response, to promote power peak-cutting and valley-filling, to promote renewable energy consumption, and to realize the friendly interaction of power grid source network and the effective control of power demand response.

\subsection{Demand response participants}

1. Power users: generally should have an independent provincial power marketing household number, industrial users in $315 \mathrm{KVA}$ and above, a single industrial user's agreed response capacity in principle not less than 500 kilowatts, The agreed response capacity of non-industrial users is not less than 200 kilowatts in principle. The electrical equipment participating in the real-time demand response should have the relevant technical capability of the load demand response management system of Xinjiang power grid.

2. Load aggregator: load aggregator is a new service enterprise developed by demand response. It mainly provides users with professional demand response technology and efficient consulting services. It obtains benefits by aggregating demand response resources and acting to participate in demand response capacity and electricity energy bidding. The enterprise should be a power sales company or a company with the qualification of "power demand side management service organization in industrial field" qualification.

3. Power sales companies: power sales companies can represent qualified industrial and commercial users to participate in the pilot, provide related transaction consulting and related technical services.2. Safetyoriented, market operation. Under the premise of meeting the requirements of safety production, ensure the safety of power grid operation, user safety production. In the way of marketization, users are guided to participate in the system adjustment, the price is encouraged to participate in the demand response, the necessary administrative means are used to protect the bottom, the load balance and the peak filling are realized.

Load side resources can be divided into four categories according to response speed: millisecond (less than 1 second), second (less than 1 minute), minute (less than 30 minutes), hour (generally half hour-4 hours ,1 day in advance)4. Among them, millisecond class load is mainly industrial, electric vehicle and other millisecond class interruptable load; second class load is mainly electric vehicle load, user side energy storage load, resident load, commercial building air conditioning load, industrial second class interruptable load, etc.; minute class load is mainly industrial production load, commercial building air conditioning load, agricultural load, resident load, etc.

\subsection{Electricity Demand Response Organization}

According to the operation needs of the power grid, the power demand response can be divided into peak cutting demand response and valley filling demand response. Peak cutting demand response refers to the need for users to reduce the load within a specified period of time. Valley filling demand response refers to the need for users to increase the load within a specified period of time.

According to the way and response time of guiding user response, power demand response can be divided into economical agreed demand response and emergency real-time demand response. The agreed demand response refers to the demand response that is invited before the response date. Real-time requirement response refers to the requirement response that receives the relevant platform instruction and starts execution within 5 minutes.

In order to improve the capacity of new energy absorption and make effective use of the disposal capacity that may appear in the difficult period, by guiding the power users to adjust the production plan (including electric vehicle charging green electricity transaction, etc.), increase the load of the difficult period.

To sum up, the power demand response organization of a provincial power grid is divided into three modes: emergency real-time demand response, economical agreed demand response and new energy additional demand response. Among them, the economic real-time demand response carries on the transaction organization through the instruction, the economic agreement demand response carries on the transaction organization through the invitation, and the new energy additional demand response according to the emergency degree, You can use both instructions and solicitation to organize transactions.

\subsection{Directs the issuing of trading organizations}

Load side resources with second or minute response ability, through the load aggregator agent or directly participate in the command response transaction, according to the principle of "unilateral bidding, marginal clearance" to determine the clearance results, when the capacity shortage or power grid negative backup shortage, The winning bidder provides positive and negative backup services to the power grid in time.

The trading center issues directive response transaction information through the power trading platform, including directive response positive standby or negative standby capacity demand, quotation upper and lower limits and so on. Load aggregators and a class of responding users directly involved in the transaction declare the market according to the regulations. The declaration information includes positive standby or negative standby response capacity, capacity price, etc. The trading center adopts the unilateral bidding mode, according to the principle of "price first, time first, capacity first ", according to the user declared price from low to high, until the capacity accumulation of the last market body is equal to the positive standby or negative reserve capacity demand value. If the clearing price is determined by the quotation of two or more market entities, the clearance amount shall be allocated 
according to the proportion of declared capacity in each period.

Select the load of the winning bidder 1 hour before the load response is performed as the baseline load. The baseline load of the load aggregator is derived from the baseline load of its aggregate response to the user.

According to the actual response effect on the day of call, whether the winning subject is adjusted according to the winning capacity, and the actual response capacity is calculated by the difference between the actual load and the baseline load in the response period through the determination of the load baseline.

(1) The formula for calculating the actual response capacity of a positive standby response transaction is:

$P_{\text {Response Capacity }}=P_{\text {Baseline Average Load }}-P_{\text {Actual Load }}$

(2) The formula for calculating the actual response capacity of a negative standby response transaction is:

$P_{\text {Response Capacity }}=P_{\text {Actual Load }}-P_{\text {Baseline Average Load }}$

When the actual response capacity of the winning bidder is greater than or equal to $80 \%$ of its clearance capacity, it is regarded as an effective response, otherwise it is regarded as an invalid response.

\subsection{Solicitation trade organizations}

When the load forecasting is high or the power grid peak-shaving capacity is insufficient to increase the flexibility of power grid operation, the load side resources with minute or hour response ability are invited by the trading center.

The trading center publishes the solicitation response transaction information through the power trading platform, including the solicitation response peak cutting, filling trading capacity demand, quotation upper and lower limits, response time period and so on. Load aggregators and a class of responding users directly involved in the transaction declare the market according to the regulations. The declaration information includes peak cutting, filling capacity, response price, response time period and so on. According to the principle of "price first, time first, capacity first ", the trading center adopts the method of centralized bidding and marginal clearing.

According to the actual response effect on the day of call, whether the winning subject is adjusted according to the winning capacity, and the actual response capacity is calculated by the difference between the actual load and the baseline load in the response period through the determination of the load baseline.

(1) The formula for calculating the actual response capacity of peak-cutting response transactions is as follows:

$$
P_{\text {Response Capacity }}=P_{\text {Baseline Average Load }}-P_{\text {Actual Load }}
$$

(2) The formula for calculating the actual response capacity of the fill-in response transaction is as follows:

$$
P_{\text {Response Capacity }}=P_{\text {Baseline Average Load }}-P_{\text {Actual Load }}
$$

When the actual response capacity of the winning bidder is greater than or equal to $80 \%$ of its clearance capacity, it is regarded as an effective response, otherwise it is regarded as an invalid response.

\section{SYSTEM SUPPORT AND IMPLEMEN- TATION}

The technical framework of demand response spot market is mainly composed of three core functions: basic support, advanced application and market management. The basic support class includes two supporting modules: data management and system management; advanced application class consists of four advanced application modules: transaction security check, electric energy measurement system, day market, real-time market, etc. The overall structure of the advanced application class is shown in figure $1^{[9-10]}$.

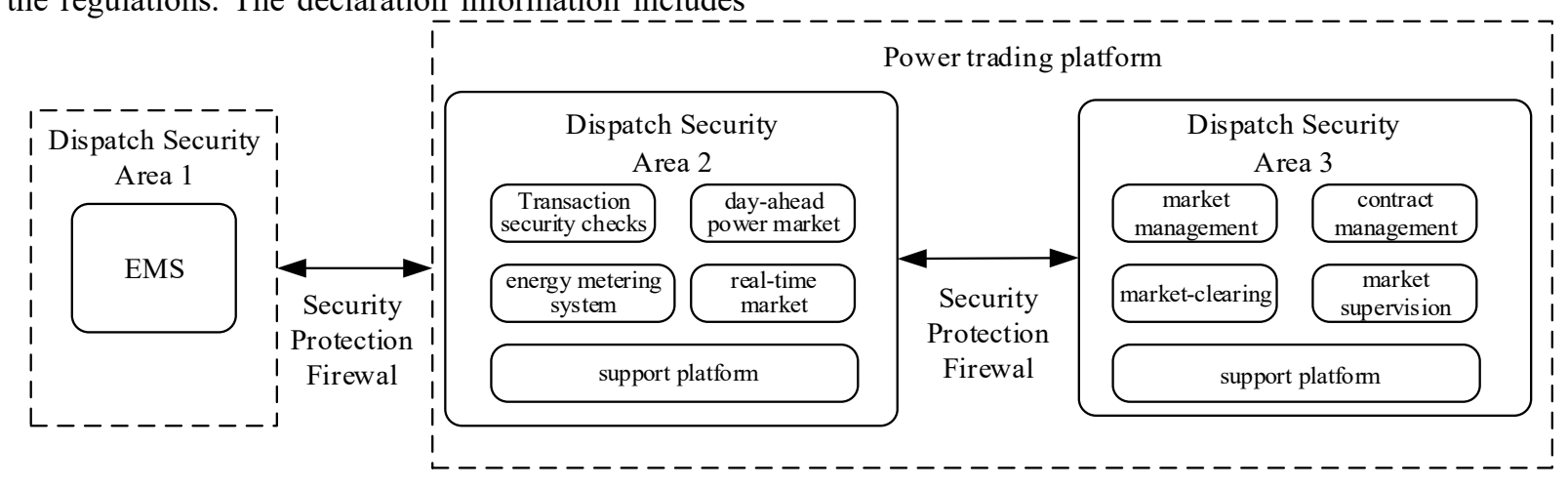

Figure 1. The overall structure of the power demand response trading system

Demand response spot trading process is:

(1) Information dissemination. According to the load forecast, release the response quantity and response time, organize the power user to declare and participate in the demand response, as the reserve resource.

(2) Unilateral bidding transactions. Through the power trading platform to the main body of the market, declare the power users who participate in the demand response before the day to carry out unilateral market bidding transactions. The transaction needs to declare the response quantity and the compensation price, in which the response quantity is based on the power trading platform large user declaration response quantity or the power sale company agent user response quantity plus sum, the compensation price is the compensation benchmark price for each response 1 kilowatt load. 
(3) Market clearing. According to the compensation base price from low to high, the declaration time from before to after the order of unified clearance, clearance price for the last 1 kilowatt response to the transaction price. Users who do not clear or participate in the bidding perform fixed compensation benchmark prices.

(4) Response execution. The invited subject shall carry out the demand response on time. According to the actual situation of power supply and demand, the company can apply for suspension of demand response and issue cancellation order. However, ensure that the cancellation order is delivered to the market body 1 hour before the original response period, otherwise the default is confirmation of execution.

(5) Evaluation of results. Through the real-time monitoring of power trading platform, automatic recording and judging the effect of demand response implementation. The power information acquisition system provides data support for the approved user gate load response and response time. If the enterprise's own platform is connected to the power trading platform and the power supply company gate meter can not be measured, the response shall be determined by the company's audit. After the evaluation of demand response effect is completed, the relevant data is stored for record.

\section{CONCLUDING REMARKS}

With the further promotion of source network load friendly interaction, changing the demand of users through demand response can promote the optimization of power generation on the power side and then improve the capacity of new energy generation. Through the analysis of the demand of new energy consumption in a provincial power grid, the power demand response trading system suitable for new energy consumption is put forward. With the help of market mode, price mechanism and compensation mechanism, the system promotes the end users to participate in the market operation and price decision of new energy consumption. The system is widely used in the same type of power grid.

\section{Acknowledgment}

This work is supported by the Zhejiang Provincial Department of Water Resources under Grant RC2016, the Zhejiang Provincial Natural Science Foundation of China under Grant LD21F050001 and Development Project of Zhejiang Province under Grant 2021C03019

\section{References}

1. Hongwei Lu, Jian Du, Hui Zhang, et al. High energy storage capacitance of defluorinated polyvinylidene fluoride and polyvinylidene fluoride blend alloy for capacitor applications[J]. Journal of Applied Polymer Science, 2020, 137(36):48-54
2. CHEN Linghui. Research on load balancing and decentralized dispatching method of renewable energy power system $[\mathrm{J}]$. Power System and Clean Energy, 2019, 35(12):60-66.

3. DING Yi, HU Yishuang, CUI Wenqi. Practices and en-lightenment of foreign power demand response $[\mathrm{J}]$. Power Demand Side Management, 2019, 21(2):1-4.

4. MA Jinjie, XU Zhengan. The exploration and practice of "valley shaft"demand response in Jiangsu grid[J]. Power Demand Side Management, 2018, 20(6):50-52.

5. ZENG Ming, WU Geng, Wang Haojing, et al Regulation strategies of demand response considering user satisfaction under smart power background[J]. Power System Technology, 2016, 40(10):2917-2923

6. HU Zhaoguang. Applicaiont of Demand Side Management to China[J]. Automation of Electric Power Systems, 2001,25(1):41-44

7. LIU Jian, WANG Shuang-hu, MING Zheng-feng. Optimal Peak Load Shifting Plan for Demand Side Management [J].Automation of Electric Power Systems, 2006, 30(8): 47-51

8. QIU Chenguang, CHENG Jinmin, LI Xinjia, et al. Inter-mittent load selection and recovery strategy for networkload interactive user[J]. Electric Power EngineeringTechnology, 2018, 37(4):33-37, 70.

9. Wenyi Zhang, Wei Wei, Laijun Chen, Boshen Zheng, Shengwei Mei. Service pricing and load dispatch of residential shared energy storage unit[J]. Energy, 2020, 202:46-51

10. Giuseppe Graber, Vito Calderaro, Vincenzo Galdi, Antonio Piccolo. Battery Second-Life for Dedicated and Shared Energy Storage Systems Supporting EV Charging Stations[J]. Electronics, 2020, 9(6):36-41 